\title{
Anti-hyperglycemic Effect of Psidium guajava Leaf Infusion
}

\author{
Rizda Nurul Zartiana, ${ }^{1}$ Samsudin Surialaga, ${ }^{2}$ Hikmat Permana ${ }^{3}$ \\ ${ }^{1}$ Faculty of Medicine Universitas Padjadjaran, ${ }^{2}$ Department of Biochemistry and Molecular \\ Biology Faculty of Medicine Universitas Padjadjaran, ${ }^{3}$ Department of Internal Medicine Faculty of \\ Medicine Universitas Padjadjaran/Dr. Hasan Sadikin General Hospital Bandung
}

\begin{abstract}
Background: Prevalence of diabetes mellitus is estimated to increase annually. Numerous people use traditional medicine, such as the Psidium guajava leaf to prevent this disease. This study aimed to analyse the effect of Psidium guajava leaf to inhibit glucose absorption in intestine epithelial membrane of wistar rats.

Methods: This laboratory experimental study used 5 wistar rats as subjects in the Laboratory of Biochemistry at Padjadjaran University from 10-26 October 2012. All rats were given three solutions by in situ perfusion method. The first was $25 \mathrm{ml} \mathrm{3.0} \mathrm{X} \mathrm{10-3} \mathrm{M} \mathrm{glucose} \mathrm{solution,} \mathrm{the} \mathrm{second} \mathrm{was} 25 \mathrm{ml} 3.0 \mathrm{X} 10-3 \mathrm{M}$ glucose solution with $1 \mathrm{ml}$ Psidium guajava infusion added, and the third was $25 \mathrm{ml} 3.0 \mathrm{X} 10-3 \mathrm{M}$ glucose solution. The sample from each solution was taken five times at $0,15,30,45$, and 60 minutes after the solutions were given. The spectrophotometer was to quantify the concentration of glucose from the samples. Data were analyzed using Friedman and Wilcoxon test.

Results:The means of glucose concentration for each solution from the first solution to the third were 6.126 $\mathrm{mg} / \mathrm{dl}, 2.447 \mathrm{mg} / \mathrm{dl}$, and $5.345 \mathrm{mg} / \mathrm{dl}$. The probability value showed significant difference between the first and second solutions ( $\mathrm{p} \leq 0.05)$.

Conclusions: Psidium guajava leaf infusion can inhibit glucose absorption in wistar rat intestine and the effect is reversible. [AMJ.2015;2(4):546-9]
\end{abstract}

Keywords: Glucose absorption, in situ perfusion, infusion, Psidium guajava leaf

\section{Introduction}

Diabetes Mellitus is a symptom resulting from impaired metabolism, accompanied by a condition with very high levels of glucose or commonly called hyperglycemia. This occurs due to the lack of hormone insulin; or the diminishing effectiveness of hormone insulin; or both. Based on its etiology, Diabetes Mellitus was classified into four types: Type 1 Diabetes, Type 2 Diabetes, Gestational Diabetes, and Other specific types. ${ }^{1}$

Based on existing data, prevalence of diabetes mellitus worldwide was $2.8 \%$ in 2000 and it was estimated to become $4.4 \%$ in 2030. The number of people with Diabetes Mellitus is projected to rise from 171 billion in 2000 to 366 million in 2030. Besides, there are 10 countries predicted to have the highest number of people with Diabetes Mellitus and the "top four" countries are India (79,4 million), followed by China (42,3 million), United States (30,3 million), and Indonesia $(21,3 \text { million })^{2}$

One of the risk factors associated with diabetes is consuming food carbohydrates in excess. Carbohydrates are easy to digest and absorbed, so it can increase thelevel of blood glucose faster. ${ }^{3}$ Therefore, lots of people use herbs which have an effect to reduce blood glucose level.

One of the herbs is guava or Psidium guajava. A recent Ethnopharmalogical study explained that the shaft, the fruit, and the leaves from Psidium guajava had been used in many countries as treatment of diabetes mellitus. ${ }^{4}$ A previous study also showed that Psidium guajava leaf extract can inhibit the activity of maltose, sucrose, and $\alpha$-amylase enzyme, so it can lower level of blood glucose. ${ }^{5}$ This study aimed to analyse the effect of Psidium guajava leaf to inhibit glucose absorption in intestine epithelial membrane of wistar rats.

Correspondence: Rizda Nurul Zartiana, Faculty of Medicine, Universitas Padjadjaran, Jalan Raya Bandung-Sumedang Km.21, Jatinangor, Sumedang, Indonesia, Phone: +62 82115809959 Email: rizda.adiwinata@gmail.com 


\section{Methods}

This study was conducted in the Laboratory of Biochemistry at Padjadjaran University from 10-26 October 2012. Psidium guajava leaves were obtained from the Arboretum of Sains Faculty, Universitas Padjadjaran. The leaves were weighed $200 \mathrm{~g}$. then chopped. Two pots were required to make the infusion. Next, water was added in the first pot and the second pot was put within. Then, $200 \mathrm{ml}$ distilled water was poured to the second pot, and the chopped leaves were put within and stewed for 15 minutes at a temperature of 900C. Afterward, the infusion was filtered with a flannel fabric and poured into a measuring glass to make sure it was $100 \mathrm{ml}$ infusion.

This study used the complete randomized design for sampling method. The subjects of study are five healthy male Wistar rats (2-3 months old) weighing 150-250 g. All rats were housed first in the laboratory environment for 7 days. Then, the rats were made to fast for 18-24 hours however were still given access to water.

The in situ perfusion tool was made by the Sains Faculty of Institut Teknologi Bandung (ITB) and designed by P. Soedigdo and Marsongkohadi. All the rats were totally anesthetized using $1.15 \mathrm{ml} / 100 \mathrm{mg}$ body weight of Ketamine $\mathrm{HCl}$ intramuscular then, fixation was performed on board. The ventral abdomen of rats was cleaned with $70 \%$ alcohol and abdominal surgery was performed with minor surgery set. The intestine of rats (small intestine) were measured $10 \mathrm{~cm}$ from pylorus, then add $25 \mathrm{~cm}$ long for used in experiment. An incision was made at both sides of the intestine, then a cannula was tied at each side. Afterwards, the intestine was washed with $\mathrm{NaCl} 0.9 \%$ and was blown using a syringe three times alternately while the cannulas were connected with an in situ perfusion tool. After everything was prepared, the was flown to be tested. There were three solutions to be tested in this experiment. The first solution was 25 $\mathrm{ml}$ of 3.0 X 10-3 M glucose solution. The second solution was $25 \mathrm{ml}$ of $3.0 \times 10-3 \mathrm{M}$ glucose solution with $1 \mathrm{ml}$ of Psidium guajava infusion added. The third solution was $25 \mathrm{ml}$ of $3.0 \mathrm{X}$ 10-3 M glucose solution. The rats' intestine were washed and blown again each time the solution was changed. The first samples were taken every $0,15,30,45$ and 60 minutes with a sixty minute duration of experiment .

The samples to be measured were taken from the first samples as much as $50 \mu \mathrm{l}$. The samples were then added with Trichloroacetic $8 \%$ for deproteinisation. Next, the sampleswere centrifuged at $3000 \mathrm{rpm}$ speed for 10 minutes. Afterwards, about $100 \mu \mathrm{l}$ supernatant were taken and added with $1 \mathrm{ml}$ glucose reagent/ GOD-PAP. Then, the samples were incubated at $37 \mathrm{oC}$ for 10 minutes. Finally, the samples were poured into a cuvet and measured at $505 \mathrm{~nm}$ absorbance using a spectrophotometer.

The glucose level was quantified using the formula ${ }^{6}$ :

$$
\text { Glu. } \text { con }=\frac{\text { Sam. abs }}{\text { St. abs }} \text { X St.con }
$$

Note

Glu. con : Glucose concentration (mg/dl)

St. con : Standard concentration $(100 \mathrm{mg} / \mathrm{dl})$

Sam. abs: Sample absorbance

St. abs : Standard absorbance

\section{Results}

The absorption level of glucose $(\mathrm{mg} / \mathrm{dl})$ for all rats was presented in Table 1 . The means of the first and second solutions were calculated and compared to see if there was any effect of the second solution.

There was quite a big difference between means of both solutions which might prove that the second solution could inhibit the glucose absorption process. Thus, the level of glucose which was inhibited must be quantified, using the formula. ${ }^{6}$

Table 1 Absorption Level of Glucose (mg/dL) for Each Solution

\begin{tabular}{|c|c|c|c|c|c|c|}
\hline \multirow[b]{2}{*}{ Treatment } & \multicolumn{5}{|c|}{ Absorption Level of Glucose (mg/dL) } & \multirow{2}{*}{$\begin{array}{c}\text { Mean of } \\
\text { Absorption } \\
\text { Level of Glucose } \\
(\mathrm{mg} / \mathrm{dL})\end{array}$} \\
\hline & Rat 1 & Rat 2 & Rat 3 & Rat 4 & Rat 5 & \\
\hline 1st Solution (glucose) & 8.728 & 5.984 & 9.009 & 3.789 & 3.119 & 6.126 \\
\hline $\begin{array}{l}\text { 2nd Solution (glucose with } \\
\text { infusion) }\end{array}$ & 2.023 & 1.166 & 3.934 & 2.763 & 2.347 & 2.447 \\
\hline 3rd Solution (glucose) & 5.954 & 6.736 & 6.847 & 3.842 & 3.344 & 5.345 \\
\hline
\end{tabular}




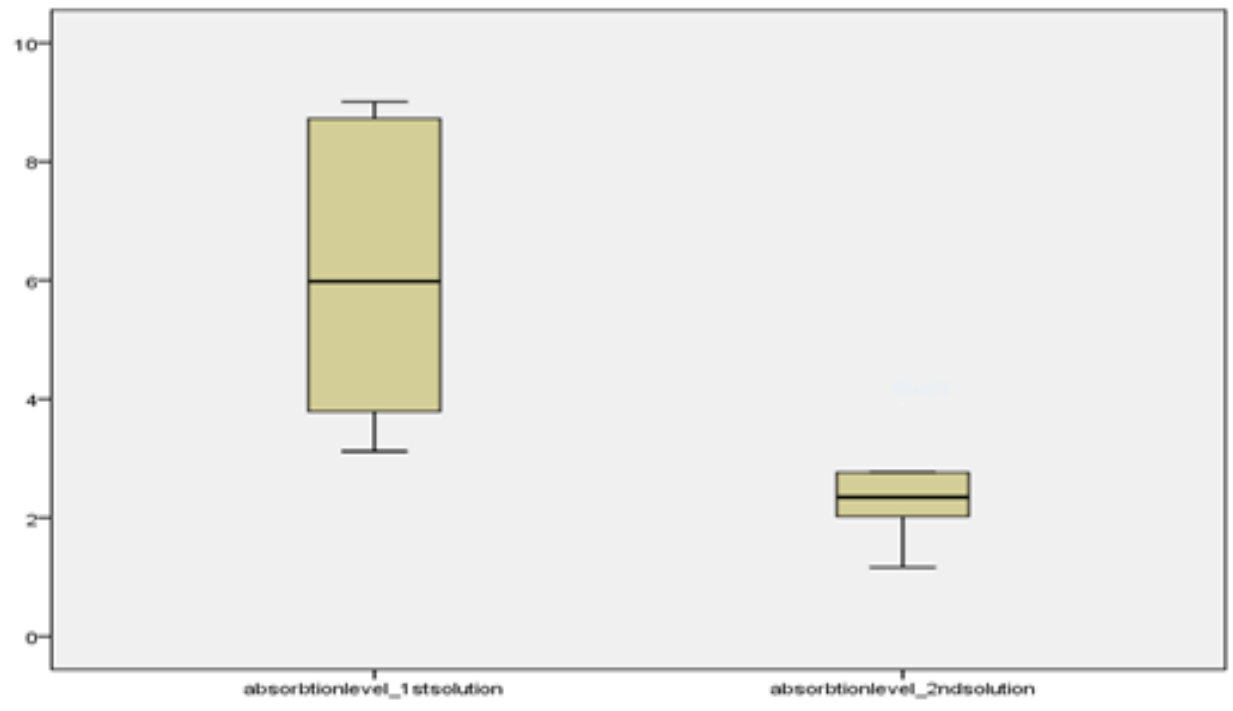

Figure 1 Comparison of Means of Absorption Level of Glucose Between $1^{\text {st }}$ and $2^{\text {nd }}$ Solution

The level of glucose which was inhibited by the Psidium guajava infusion was 60.056 $\%$ according to absorption level of the first solution. Then, the first solution was compared to the third solution to find out if the effect was reversible or irreversible (Figure 2).

Normality of the data were examined by using theSaphiro-Wilk test. The result showed that the data were abnormally distributed ( $p$ $<0.05)$. Furthermore, the transforming of data was performed however, the result of SaphiroWilk test was still abnormal. Therefore, Friedman and Wilcoxon tests were carried out to analize the data statistically.

The Friedman test showed probability value was $0.022(\mathrm{P}<0.05)$, meaning at least two measurements were different significantly. Then post-hoc wilcoxon test was performed and showed that the second solution, which contained Psidium guajava infusion, had

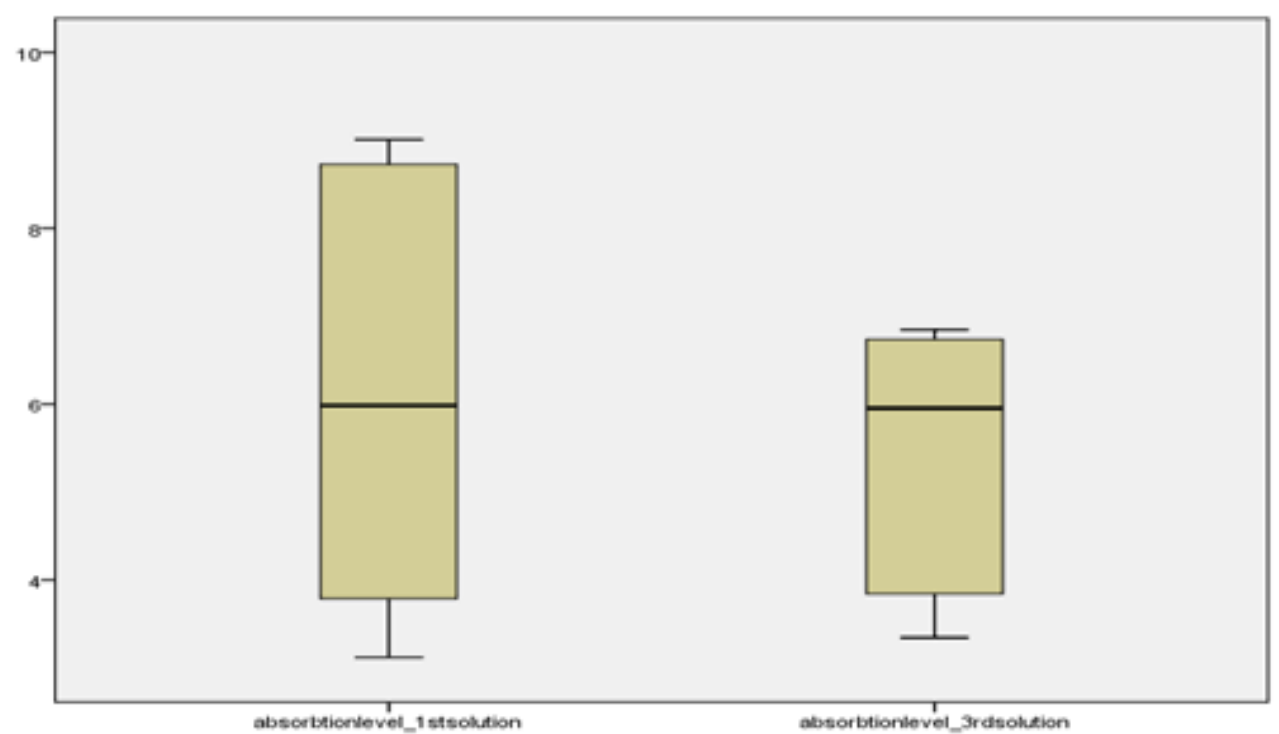

Figure 2 Comparison of Means of Absorption Level of Glucose Between $1^{\text {st }}$ and $3^{\text {rd }}$ Solution 
significant effect to inhibit glucose absorption compared with the first solution $(\mathrm{P}=0.043)$. On the other hand, the third solution has no differences with the first solution so that the effect of Psidium guajava infusion was reversible.

\section{Discussion}

The result of this study showed Psidium guajava infusion was able to inhibit glucose absorption in wistar rats intestine. It can be associated with a previous study by Deguchi and Miyazaki ${ }^{5}$. The study used guava leaf extract or GvEx as material for treatment. The rats were divided into control and treatment groups, then gave GvEx per-oral to thetreatment group. At the end of the research, it was proved that GvEx has anti-hyperglycemic effect. With a different method using streptozotocin-induce diabetic mice (type 1 Diabetes Mellitus), GvEx is able to lower post prandial blood glucose level significantly. The same condition occurs in another study using human as subject., , $^{-9}$

The inhibitory effect that is produced by Psidium guajava infusion derives from a group of phenolic hydroxil contained in the Psidium guajava leaf. The phenolic hydroxil group is in the form of polyphenol such as peduncladgin, casuarinin, and isostrictin. In addition there are also polymerized polyphenol content consisting of ellagic acid, cyanidin, and others low molecular weight polyphenols. ${ }^{5,10}$ Polyphenols are able to inhibit the enzyme $\alpha$-amylase, maltase, and sucrose. Those enzymes digest carbohydrates into a glucose form which will be absorbed through the intestines. By inhibiting this enzyme, no glucose or other monosaccharides are formed, so there is no absorption. ${ }^{5,11}$

This study demonstrated that Psidium guajava leaf infusion could also directly inhibit glucose absorption. Psidium guajava not only inhibited the breakdown of carbohydrates into glucose but also inhibited the absorption of glucose itself.

On the other hand, comparison between the first and second solution showed no significant difference for level of glucose absorption. This occurred because by washing the intestine using $\mathrm{NaCl} 0.9 \%$ and blowing it could eliminate the inhibitory effect of polyphenol in Psidium guajava infusion. It can be concluded that the effect of infusion is reversible. However, further study is needed to confirm this conclusion.

\section{References}

1. Gardner DG, Shoback DM, Greenspan FS. Greenspan's basic \& clinical endocrinology. 8th ed. San Francisco: McGraw-Hill Medical; 2007.

2. Wild S, Roglic G, Green A, Sicree R, King H. Global prevalence of diabetes estimates for the year 2000 and projections for 2030 . Diabetes Care. 2004;27(5):1047-53.

3. Willett W, Manson J, Liu S. Glycemic index, glycemic load, and risk of type 2 diabetes. Am J Clin Nutr. 2002;76(1):274S-80S.

4. Gutierrez RM, Mitchell S, Solis RV. Psidium guajava: a review of its traditional uses, phytochemistry and pharmacology. J Ethnopharmacol. 2008;117(1):1-27.

5. Deguchi Y, Miyazaki K. Anti-hyperglycemic and anti-hyperlipidemic effects of guava leaf extract. Nutr Metab. 2010;7(1):9.

6. Fortress Diagnostic. Glucose (GOD-PAP) liquid stable. Antrim: Fortress Diagnostics Limited; 2009. p. 1-2.

7. Ojewole JAO. Hypoglycemic and hypotensive effects of Psidium guajava Linn. (Myrtaceae) leaf aqueous extract. Methods Find Exp Clin Pharmacol. 2005; 27(10):689-95.

8. Mukhtar HM, Ansari SH, Ali M, Naved T, Bhat ZA. Effect of water extract of Psidium guajava leaves on alloxan-induced diabetic rats. Pharmazie. 2004;59(9):734-5.

9. Wang B, Liu HC, Ju CY. Study on the hypoglycemic activity of different extracts of wild Psidium guajava leaves in Panzhihua Area. Sichuan Da Xue Xue Bao Yi Xue Ban. 2005;36(6):858-61.

10. Deguchi Y. Effect of guava tea on postprandial blood glucose and diabetes. Assoc J Jpn Soc Med Use Funct Foods. 2006;3(6):439-45.

11. Wang B, Liu HC, Hong JR, Li HG, Huang CY. Effect of Psidium guajava leaf extract on alpha-glucosidase activity in small intestine of diabetic mouse. Sichuan Da Xue Xue Bao Yi Xue Ban. 2007;38(2):298-301. 